\title{
PENGARUH LATIHAN AGILITY LADDER EXERCISE TERHADAP KETERAMPILAN DRIBLING BOLA DALAM PERMAINAN SEPAKBOLA
}

\author{
Irfan $^{1^{*}}$, Nurul Umansyah ${ }^{2}$ \\ ${ }^{1}$ Program Studi Pendidikan Jasmani Olahraga Kesehatan dan Rekreasi, STKIP Taman Siswa Bima, Bima, Indonesia \\ ${ }^{2}$ Program Studi Pendidikan Jasmani Olahraga Kesehatan dan Rekreasi, STKIP Taman Siswa Bima, Bima, Indonesia \\ *irfanhmt05@gmail.com*
}

(Received: August 2019/Revised: September 2019 / Accepted: November 2019)

ABSTRAK: Tujuan penelitian ini untuk mengetahui ada pengaruh latihan agility ladder exercise terhadap
keterampilan dribbling bola dalam permainan sepakbola. Jenis penelitian adalah eksperimen yaitu suatu
metode yang dilakukan dengan cara memberikan perlakuan terhadap subyek penelitian. Penelitian ini
dilakukan pada siswa putra kelas VIII yang berjumlah 26 orang, teknik pengambilan sampel yang digunakan
dalam pelitian ini adalah teknik proposional random sampling dengan cara undian. Instrumen dalam
penelitian ini menggunakan tes dan pengukuran. Hasil penelitian diperoleh data berdasarkan analisis
latihan agility ladder exercise terhadap keterampilan dribbling bola. Dengan besaran nilai t-hitung 8.061
lebih besar dari nilai t-tabel 2.064 , sehingga dari hasil penelitian ini dapat di simpulkan bahwa, Ada pengaruh
yang signifikan setelah diberikan latihan agility ladder ecercise terhadap keterampilan dribbling bola pada
siswa putra kelas VIII Sekolah Menengah Pertama Negeri 1 Wawo Kabupaten Bima.
KATA KUNCI: Agility ladder exercise, dribbling bola, sepakbola.

ABSTRACTS: The purpose of this study was to determine the effect of agility ladder exercise on ball dribbling skills in football games. This type of research is an experiment which is a method carried out by giving treatment to research subjects. This research was conducted in male students of class VIII, amounting to 26 people, the sampling technique used in this research is the technique of proportional random sampling by lottery. The instruments in this study used tests and measurements. The results of the study obtained data based on the analysis of agility ladder exercise training on ball dribbling skills. With a magnitude value of 8.061 greater than the value of $t$-tabel 2.064 , so the results of this study can be concluded that, there is a significant effect after being given agility ladder training to the ball dribbling skills of male students in class VIII SMP Negeri 1 Wawo Kabupaten Bima.

KEYWORD: Agility ladder exercise, ball dribbling skill, soccer.

\section{PENDAHULUAN}

Sepakbola merupakan permainan yang menggunakan waktu 2 x 45 menit. Dalam waktu 90 menit tersebut, seorang pemain sepakbola dituntut untuk selalu bergerak. Tidak hanya sekedar bergerak, namun dalam bergerak tersebut masih melakukan berbagai gerak fisik lainnya seperti berlari sambil melakukan dribbling bola, berlari kemudian harus berhenti tiba-tiba, berlari sambil berbelok 90 derajat, bahkan 180 derajat. Melompat (jumping), meluncur (sliding) beradu badan (body-charge), bahkan terkadang berlanggar dengan pemain lawan dalam kecepatan tinggi. Semua itu memerlukankualitas kondisi fisik pada tingkat tertentu, untuk bisa memainkan bola tersebut dengan baik (Apriyadi, 2014).

Dribbling bola dalam sepakbola sangatlah penting. Karena dribbling adalah salah satu teknik dasar dalam sepakbola. Ketika pemain tidak menemukan teman yang bisa diumpan, pemain harus dribbling bola tersebut. Demikian pula ketika mengumpan akan berakibat offside, pemain bisa jadi harus menggiring. Yang pada dasarnya dibedakan menjadi dua; closed dribbling dan speed dribbling. Closed dribbling dilakukan dengan kontrol penuh atas bola, dilakukan ketika 
bola tidak benar-benar aman dari lawan. Pada closed dribbling, bola tidak boleh berada lebih dari 1 meter dengan jarak kaki. Adapun speed dribbling hanya mampu meningkatkan kecepatan pemain. Pada speed dribbling, pemain mampu melakukan dribbling bola secepatnya dengan berlari secepatcepatnya bisa dilakukan dengan menendang bola kedepan lalu kejar sekuat-kuatnya. Namun syaratnya, harus mampu bebas dari tekanan lawan.

Permainan sepakbola tidak hanya mengusai teknik dasar saja, namun hal penting juga yang harus disiapkan adalah kondisi fisik yang ideal. Sajoto (2005:105) memberikan pendapat bahwa seorang olahragawan tidak akan dapat melakukan teknik-teknik secara sempurna jika kondisi fisiknya tidak baik, kondisi fisik merupakan modal dasar untuk mencapai keterampilan yang optimal.

Kondisi fisik adalah salah satu unsur pendukung yang sangat penting untuk menunjang performa pemain. Kondisi fisik akan mempengaruhi permainan secara signifikan. Komponen-komponen kondisi fisik yang harus dimiliki pemain sepak bola adalah 1). Speed (Kecepatan), 2). Strength (Kekuatan), 3) Endurance (Daya tahan), 4). Flexibility (Fleksibilitas), 5) Accuracy (Akurasi), 6). Power (DayaLedak), 7). Coordination (Koordinasi), 8). Reaction (Reaksi), 9). Balance (Keseimbangan), 10). Agility (Kelincahan) (Ismoyo, 2014).

Selain peningkatan kualitas kondisi fisik, para pemain dalam permainan sepakbola juga membutuhkan tingkat kelincahan yang tinggi, beberapa bentuk aktivitas dilapangan yang membutuhkan kelincahan pada saat dribbling bola sampai dribbling dengan cepat menuju gawang melewati beberapa lawan yang menjaga daerah dengan formasi tertentu. Kelincahan sangat menentukan agar bisa menerobos menghindari hadangan lawan, agar bisa memasukkan bola ke gawang lawan. Selain itu kelincahan juga bermanfaat bagi para atlit agar tidak mudah jatuh dan cedera saat berlari (Faruq, 2009:106).

Peningkatan keterampilan dalam permainan sepakbola baik berupa penguasaan teknik dasar, dan kondisi fisik, yang ideal meruapakan satu kesatuan yang tidak dipisahkan dalam permainan sepakbola. Namun demikian, untuk meningkatkan lagi ke level yang sempurna perlu didukung dengan berbagai metode latihan yang sesuai dengan perubahan sepakbola modern, misalnya metode latihan agility ladder exercise.

Latihan agility ladder exercise metode lateral run merupakan bentuk latihan yang menuntut konsentrasi tinggi dan koordinasi gerakan yang kompleks. Faktor tersebut akan mempengaruhi peningkatan momen gaya kontraksi otot, sehingga terjadi peningkatan pada koordinasi sistem keterampilan motorik yang dapat memicu meningkatnya kelincahan (Maulana, 2012).

Latihan shuttle run tersebut yang paling sering diterapkan dalam latihan sepakbola adalah dengan menggunakan agility ladder exercise. Jenis latihan ini penerapannya dengan menggunakan media kotak tangga yang disebut dengan tangga kelincahan. Kemudian untuk tehniknya dengan lari menyamping didalam trek tangga tersebut. Latihan ini sangat bagus untuk meningkatkan kelincahan lari, karena latihan ini melatih konsentrasi gerak yang tinggi.

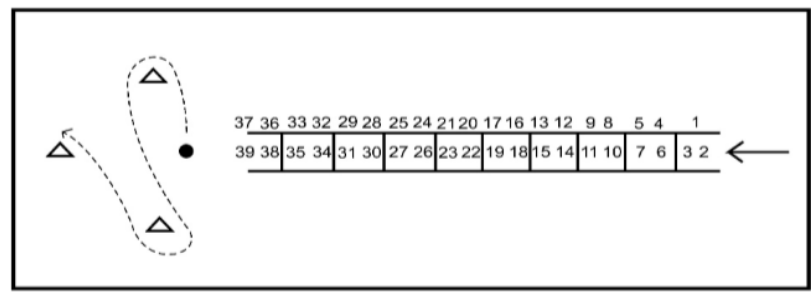

Gambar 1. Latihan Agility Ladder Exercise (Yusdianto,2013)

Metode latihan agility ladder exercise dengan tujuan untuk meningkatkan keterampilan 
permainan sepakbola. Hal demikian telah banyak diungkapkan dalam beberapa penelitian yang relavan sebelumnya, diantaranya beberapa penelitian dibawah ini.

Fajar Ismoyo (2014) dengan judul pengaruh latihan variasi ladder drill terhadap kemampuan dribbling, kelincahan, dan koordinasi pada atlet usia 12-13 menyimpulkan terdapat pengaruh latihan variasi ladder drill terhadap kemampuan dribbling pada atlet usia 11-12 tahun, yaitu sebesar $2,77 \%$, Terdapat pengaruh latihan variasi ladder drill terhadap kemampuan kelincahan pada atlet usia 11-12 tahun, yaitu sebesar 1,56\%, Terdapat pengaruh latihan variasi ladder drill terhadap kemampuan koordinasi pada atlet usia 11-12 tahun, yaitu sebesar 5,82\%.

Penelitian Muh Irkham (2015) hasil penelitiannya yang berjudul pengaruh latihan agility ladder exercise dengan metode lateral run drill terhadap peningkatan keterampilan dribbling pada pemain SSB Pelangi U17, disimpulkanan : a) ada pengaruh yang signifikan pada latihan agility ladder exercise terhadap peningkatan keterampilan dribbling, b) ada pengaruh yang signifikan pada latihan metode lateral run drill terhadap peningkatan keterampilan dribbling, c) Tidak terdapat perbedaan yang signifikan terhadap hasil akhir latihan antara latihan agility ladder exercise dan metode lateral run drill.

Hasil pengamatan peneliti yang dilakukan siswa putra kelas VIII SMPN 1 Wawo ditemukan masalah mengenai menggiring bola, kelincahan, dan konsentrasi gerak. Peneliti melakukan uji coba dengan menggunakan setengah babak permainan dimenangkan oleh kelas $X$ dan selama berlangsungnya pertandingan peneliti memantau kelas VIII pola permainannya tidak teratur yang disebabkan oleh keterampilan menggiring bola siswa.

Meningkatkan keterampilan menggiring bola siswa harus diberikan latihan khusus agar permainan yang mereka lakukan terlihat indah dan menarik ditonton. Berdasarkan latar belakang masalah, penulis mengambil sebuah rumusan masalah dalam penelitian ini yaitu apakah ada pengaruh latihan agility ladder exercise terhadap keterampilan dribbling bola dalam permainan sepakbola pada siswa putra kelas VIII SMPN 1 Wawo Kabupaten Bima.

\section{METODE PENELITIAN}

Jenis pendekatan pada penelitian ini adalah pendekatan eksperimen, yaitu suatu metode yang dilakukan dengan cara memberikan perlakuan terhadap subyek penelitian. Rancangan yang digunakan dalam penelitian ini yaitu one group pre-tes and post-test design yaitu rancangan penelitian yang terdapat pree test sebelum di beri perlakuan dan post-test setelah diberi perlakuan dengan demikian dapat diketahui lebih akurat karena membandingkan sebelum diberi perlakuan dan setelah diberi perlakuan (Sutrisno hadi, 2001).

Variabel penelitian ini bertujuan untuk mengetahui ada atau tidaknya pengaruh hasil latihan agility ladder exercise terhadap peningkatan keterampilan dribbling bola pada siswa putra kelas VIII SMPN 1 Wawo Kabupaten Bima, serta untuk mengetahui model latihan yang lebih efektif dari latihan tersebut. Untuk menghindari terjadinya salah pemahaman dalam penelitian ini, maka akan dikemukakan definisi operasional yang digunakan dalam penelitian yaitu 1) Variabel bebas adalah yang mempengaruhi dan sebagai penyebab salah satu faktor. Variabel bebas dalam penelitian ini adalah latihan agility ladder exercise. 2) Variabel terikat adalah variabel yang merupakan akibat dari variabel bebas. Variabel terikat dalam penelitian ini adalah keterampilan menggiring bola. 


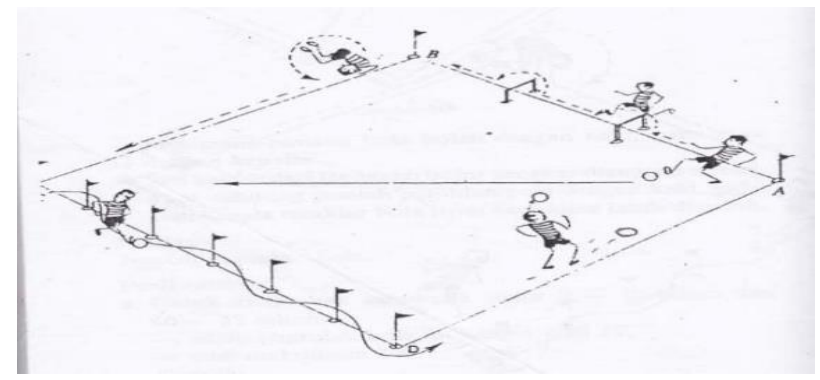

Gambar 2. Tes Keterampilan dribbling (Yusdianto 2013)

Populasi penelitian ini adalah semua siswa putra kelas VIII Sekolah Menengah Pertama Negeri 1 Wawo yang berjumlah 110, melihat sampel yang besar maka digunakan teknik rundown sampling. Sehingga dari jumlah populasi 110 orang tersebut maka yang menjadi sampel berjumlah 16 orang siswa putra di dalam penelitian ini. Instumen penelitian melalui tes keterampilan menggiring bola.

Untuk mengumpulkan data dari tes perbuatan dilakukan dengan teknik analisis data dengan tahapan-tahapan yang sesuai dengan tes yang dilakukan dalam penelitian ini.

Adapun teknik mengolah data dalam penelitian adalah dengan rumus uji $\mathrm{t}$ menurut Sugiyono dalam yanuar Haris P. (2015: 48) sebagai berikut:

$$
t=\frac{\sum D}{\sqrt{\frac{\left(N \sum D^{2}\right)\left(\sum D^{2}\right)}{N-1}}}
$$

Keterangan :

$\mathrm{D}=$ Jumlah perbedaan setiap pasangan

D 2 = Jumlah perbedaan kuadrat setiap pasangan

$\mathrm{N}$ = Banyak sampel

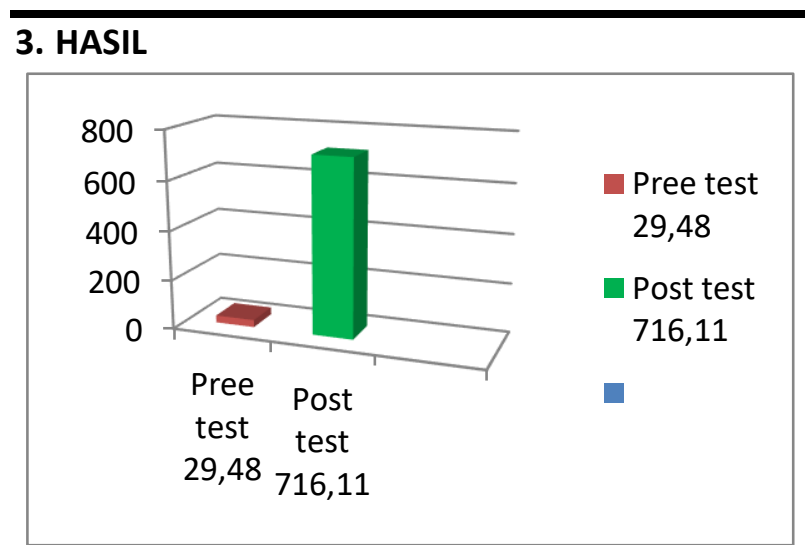

Grafik 1. Hasil Pre-Test dan Post-Tes

Berdasarkan hasil tes awal keterampilan menggiring bola dengan nilai rata-rata berjumlah 29,48, sedang setelah dilakukan perlakuan mendapatkan hasil tes akhir keterampilan menggiring bola dengan nilai rata-rata berjumlah 726,11 . Artinya ada peningkatan latihan Agility Ladder Exercise terhadap keterampilan menggiring bola.

Setelah mendapatkan nilai t-hitung dengan $\mathrm{df}$ $(\mathrm{N}-1)=25$ maka nilai $\mathrm{t}$-hitung yang menunjukan angka 8,061 dari pada $t_{\text {-tabel }}$ dengan angka 2,064 atas dasar taraf signifikan $5 \%$ berarti signifikan. Dilihat dari hasil perbandingan tersebut maka disimpulkan bahwa $\mathrm{t}_{\text {-hitung }}$ sebesar 8,061 $>\mathrm{t}$-tabel 2,064 taraf pengujian signifikan. Dengan demikian ada pengaruh latihan Agility Ladder Exercise terhadap keterampilan Dribbling bola pada Siswa Putra Kelas VIII SMP Negeri 1 Wawo Kabupaten Bima.

Sedangkan hipotesis alternatif $(\mathrm{Ha})$ yang berbunyi "Ada Pengaruh Latihan Agility Ladder Exercise terhadap Keterampilan Dribbling bola pada Siswa Putra Kelas VIII SMP Negeri 1 Wawo Kabupaten Bima" diterima. 


\section{PEMBAHASAN}

Berdasarkan hasil analisa data bahwa, setelah diberikan latihan agility ladder exercise meannya lebih besar yaitu 716.11, dibandingkan dengan sebelum diberikan latihan agility ladder exercise meannya 829.45 sehingga ada pengaruh latihan Agility Ladder Exercise terhadap keterampilan Dribbling bola pada Siswa Putra Kelas VIII Sekolah Menengah Pertama Negeri 1 Wawo Kabupaten Bima.

Hasil penelitian yang telah di eksperimenkan pada siswa putra kelas VIII SMPN 1 Wawo Kabupaten Bima dengan metode latihan agility ladder exercise terhadap keterampilan dribbling bola terdapat pengaruh yang signifikan hal demikian juga dilakukan dalam penelitian terdahulu yang dilakukan oleh Ilham Apriyadi (2014) dengan judul pengaruh agility ladder exercise dengan metode lateral run terhadap peningkatan kelincahan lari pada atlet sepakbola usia 13 di sekolah sepakbola Jaten. Disimpulkan ada pengaruh agility ladder exercise metode lateral run terhadap peningkatan kelincahan lari pada atlet sepakbola usia 13 tahun di Sekolah Sepakbola Jaten.

Bertolak dari hasil penelitian bahwa metode agility ladder exercise dapat memberikan referensi kepada khalayak di dunia sepakbola, bahwa metode ini dapat meningkatkan keterampilan dribbling bola, hal demikian sebagai efek dari latihan agility ladder exercise selama berlangsunganya penelitian. Serta didukung oleh latihan-latihan yang diberikan mengacu pada program latihan yang telah dirancang dengan penuh ketelitian, serta berpedoman pada prinsipprinsip dan beban latihan.

\section{SIMPULAN DAN REKOMENDASI}

Dengan adanya program latihan agility ladder ecercise terhadap keterampilan dribbling bola memberikan dampak yang baik terhadap keterampilan bermain sepakbola. Program latihan ini sebaiknya terus ditingkatkan dan dikembangkan dalam program latihan yang terukur dan sistematis dalam memformulasi program latihan yang tepat pada permainan sepakbola. Penelitian ini telah menemukan ada pengaruh yang signifikan setelah diberikan latihan agility ladder ecercise terhadap keterampilan dribbling bola pada siswa putra kelas VIII SMPN 1 Wawo Kabupaten Bima. Pada taraf signifikansi 5\%, ternyata lebih besar dari angka batas penolakan.

Peneliti mengajukan beberapa rekomendasi yaitu. Diharapkan kepada guru, Pembina, pelatih, supaya memberikan keterampilan mengiring bola dengan latihan agility ladder ecercise. Dengan demikian para siswa bersungguh-sungguh dalam melaksanakan latihan guna mendapatkan keterampilan menggirirng bola dengan tepat.

\section{UCAPAN TERIMAKASIH}

Dalam pelaksanaan penelitian ini tentu banyak pihak yang telah membantu peneliti dalam penyusunan awal sampai pada kelengkapan data pada saat melaksanakan penelitian di lapangan.

a. Terima kasih kepada Bappeda yang telah memberikan rekomendasi ke pada peneliti untuk melakukan penelitian di wilayah Kabupaten Bima.

b. Terimakasih kepada seluruh komponen sekolah yang telah memberikan kesempatan kepada peneliti untuk melaksanakan penelitian di SMP Negeri 1 Wawo Kabupaten Bima.

\section{REFERENSI}

Apriyadi Ilham, 2014. Pengaruh Agility Ladder Exercise dengan Metode Lateral Run terhadap Peningkatan Kelincahan Lari pada Atlet Sepak Bola Usia 13 Tahun di sekolah Sepak Bola Jaten. Surakarta: Naskah Publikasi.

Danny Mielke, 2007. Dasar-dasar Sepakbola. Bandung: Pakar Raya.

Faruq, 2009. Meningkatkan Kebugaran Jasmani Melalui Permainan Bolabasket. Surabaya: PT Gramedia Widia sarana Indonesia. 


\section{Journal of Sport and Exercise Science, Vol 2, No 2, 2019 (49-54)}

Pengaruh Latihan Agility Ladder Exercise Terhadap Keterampilan Dribling Bola Dalam Permainan Sepakbola

Fajar Ismoyo, 2014. Pengaruh Latihan Variasi Ladder Drill terhadap Kemampuan Dribbling, Kelincahan, dan Koordinasi pada Atlet Usia 12-13.

https://eprints.uny.ac.id/14377/1/skripsileng kap.pdf.

Sajoto, 2005. Peningkatan dan Pembinaan

Kekuatan Kondisi Fisik Dalam Olahraga. Semarang : Dahara Prize.

Hadi, Sutrisno. 2001. Metodologi Research, Jilid III. Yogyakarta: Andi Offset.

Maulana, Dian. 2011. Efek Penambahan Core Stability Exercisepada LatihanShuttle RunTerhadap Peningkatan Agilitypada Pemain Futsal. Jakarta: Universitas Esa Unggul Jakarta.
Muh Irkham, 2015. Pengaruh Latihan Agility Ladder Exercisedengan Metode Lateral Run Drill Terhadap Peningkatan Keterampilan Dribbling Pada Pemain Ssb Pelangi U17 TAHUN

2015. https://lib.unnes.ac.id/23328/1/6301411066. pdf

Yusdianto Yustinus, 2013. Perbedaan Pengaruh Latihan Menggiring Bola Menggunakan KuraKura Kaki Dalam Dan Kura-Kura Kaki Luar Terhadap Kecepatan Menggiring Bola Dalam Sepakbola Pada Tim Popda SMA Negeri Jumapolo Tahun 2013, Skripsi, Universitas Negeri Semarang 